\title{
Enhancing Mechanics Education through Shared Assessment Design
}

\section{Prof. Roger G. Hadgraft, University of Technology Sydney}

Roger Hadgraft BE(Hons), MEngSc, DipCompSc, PhD, FIEAust is Professor of Engineering and IT Professional Practice in the Faculty of Engineering and IT at the University of Technology Sydney. He is a civil engineer with 25 years involvement in leading change in engineering education, with a particular focus on problem/project-based learning (PBL), at RMIT, Monash, Melbourne and Central Queensland Universities. Roger is an ALTC (Australian Learning and Teaching Council) Discipline Scholar in Engineering and ICT, having co-developed the draft Australian national academic standards for the discipline. $\mathrm{He}$ is a passionate advocate of national and international cooperation in engineering education, particularly the sharing of best-practice learning materials.

\section{Prof. David Lowe, The University of Sydney}

Professor David Lowe is Associate Dean (Education) and Professor of Software Engineering in the Faculty of Engineering and Information Technologies at The University of Sydney. He has active research interests in real-time control in the web environment and remote laboratories. He has published widely including over 150 papers and three books (most recently Web Engineering: A Practitioner's Approach, McGraw-Hill, co-authored with Roger Pressman). He is a past-President of the Global Online Laboratory Consortium, and is the convenor of the Australian Engineering Associate Deans (L\&T) network.

Ms. Justine Lawson 


\section{Enhancing mechanics education through shared assessment design}

There is considerable commonality between engineering undergraduate programs in terms of content, pedagogies, course structures and assessment practices, particularly in terms of engineering fundamentals such as mechanics. Despite this, and the availability of an array of online resources, there seems to be limited commitment to sharing learning resources among teaching academics and between institutions. Further, there seems to be a specific resistance to sharing those materials that support the teaching and learning of technical content ${ }^{1}$.

Collaborations seen in research networks seem not to have equivalent presence in teaching and learning, despite a literature that points to the benefits of sharing curriculum resources ${ }^{2,3}$.

A few projects funded by the Federal Office for Learning and Teaching (OLT) in Australia have made freely available resources as deliverables (A proactive approach to addressing student learning diversity in engineering mechanics ${ }^{4}$; Promoting student engagement and continual improvement: Integrating professional quality management practice into engineering curricula ${ }^{5}$; Remotely accessible laboratories: Enhancing learning outcomes ${ }^{6}$ and many more ${ }^{7}$ ). There has been varied uptake of these, however, and the long-term maintenance of online resources is problematic. There is also a literature that identifies sustainability challenges with open educational resources including funding and intellectual property rights ${ }^{3}$.

It could be argued that failure to provide resources and, concomitantly the uptake by teaching academics of such resources impedes student access to these resources and therefore impacts their learning. It also contributes to inefficiencies brought about by work duplication. The reasons for limited uptake of resources are both institutional and individual. However, there are nuances to what is meant by a resource, how resources are modified by academics and where in a program they might be used ${ }^{1}$. For the purposes of this paper, we are looking at resources designed to assist in the learning and teaching of engineering mechanics.

This paper presents the results of a workshop held as part of a project, funded by the Australian Council of Engineering Deans (ACED), to promote curriculum sharing across the 35 universities in Australia that teach engineering. It includes a description and analysis of the activities, an analysis of the workshop evaluation as well as one participant's reflection on the process.

\section{Investigating resource use}

The preliminary project investigations mapped the local known in terms of the national and international literature and Australian learning and teaching projects on resource sharing initiatives, with emphasis on mechanics. A collection of repositories and online resources was compiled. Several textbook publishers were also contacted to determine the availability of resources and/or assessment items.

A short survey of participating universities enabled an evaluation of some resources and an insight into how and why academics develop teaching resources. Three meta-resources ${ }^{8-10}$ were sent to project team members for distribution and evaluation amongst teaching academics. The resources were in the areas of foundation content in mechanical/civil (mechanics) and electrical engineering (circuit analysis).

The following questions were posed:

1. How useful is this resource?

2. How would you use it?

3. If not useful, why wouldn't you use it?

4. Do you use other, better resources to teach the same concept? 
5. What are they?

Further, each project team member was asked for their thoughts on the resources:

1. With whom did you share the resources and what was the feedback?

2. Did you think the resources were useful? Why? How?

3. Do you know of other resources to teach the same concept?

4. What do you see as some of the barriers to resource sharing - particularly in the area of technical content?

\section{Results}

We received feedback from ten individuals from four universities. In summary:

1. Most participants thought the resources were interesting but noted that it was difficult to navigate because there was no sense of cataloguing

2. Determining quality and relevance was time-consuming and a likely barrier to use

3. There was a preference for peer reviewed resources

4. Many respondents felt that they would refer the resources on to students or make them available as additional materials for students

5. Nobody indicated that they would replace their existing resources with any of these, opting instead to integrate or add to existing resources

6. Several academics commented that they develop their own resources and personalise the delivery of their courses. For this reason, they need online resources to be readily adaptable or easily modified.

A couple of respondents identified the need to include involvement of students in considering the value and uptake of shared resources. Similarly, the propensity for academics to duplicate materials that they know are widely available means that there is scope to consider more deeply the value of personalised and contextualised resources for both academics and students.

\section{Discussion}

It is possible that the practice of contextualising and personalising resources is the single biggest barrier to sharing resources and might be insurmountable given the need for academics to make meaning and sense of content for both themselves and their students. This means despite the volume of materials, even if it was curated and assessed for quality, academics might still be reluctant to use them without making subtle or substantial changes. Academics would still need to determine the suitability for their particular use. As one academic noted:

\section{It might possible be able to get some interesting ideas for things like tutorial problems or exam questions, but even with these I suspect that it would probably take me longer to sift through all the information, find good examples, and then adapt them to suit my unit than it would take me to just write things from scratch myself.}

Interestingly, in a related ACED project on e-portfolios, there is a demonstrated willingness to share practice and ideas about e-portfolio use. Equally, the OLT project on assessing Final Year Engineering Projects enabled substantial sharing of practice and course materials. It is possible that this sharing was motivated by the need to have wider (course/program) practice affirmed and improved and is subtly different to sharing open source materials for individual teaching purposes.

The team wondered about the conditions under which resource collaborations then might be most successful and pondered the work completed by the Australian Medical Assessment 
Collaboration (AMAC), ${ }^{11}$ which demonstrated the possibility of sharing assessment items among medical faculties before widespread sharing of curriculum resources.

An email was circulated asking Associate Deans (Learning \& Teaching) (ADLTs) to indicate their willingness to participate in a 1.5-day pilot workshop designed to peer critique typical assessment items in a particular area (covering different knowledge areas and different levels of expertise). The intention was to develop both a common pool of assessment items from which academics could draw but also to begin to develop shared expectations of curriculum knowledge in that area. The pilot workshop would inform a wider OLT project that would build assessment items across year groups or programs.

\section{Pilot workshop}

In response to the email, 16 universities indicated a willingness to take part in a pilot workshop with an additional 4 possibilities. Participants were asked to bring 5 or more typical assessment questions within a particular area. These would be evaluated for quality, relevance and difficulty.

The guidelines developed by $\mathrm{AMAC}^{11}$ were useful here, particularly for multiple choice items, such as:

1. indicators for knowledge/ability

2. creativity

3. relevance

4. format versus content

5. difficulty

For a valid assessment of knowledge or ability, the question first must be valid to the field of study. The question should also minimise the number of false positives (perhaps guessing) and false negatives (answering incorrectly, despite having the required knowledge). The AMAC report presents $\mathbf{1 7}$ guidelines for writing effective multiple choice questions. The AMAC report also provides guidelines in writing creative questions that draw upon real life, relevant examples in order to test higher order thinking.

In addition, participants considered the roles and importance of particular questions and the implications if students do not answer correctly. Examination of the assessment items also enabled the development of 'curriculum universals', that is, the curriculum content that is seen as central to a particular subject or unit. In this sense, wider considerations for curriculum design can be made.

Apart from ensuring quality assessment tasks, the question bank (if it could be developed) would provide a benchmarking tool for all universities to use. It would enable each university's students to be compared with students at other universities, which is very useful in terms of benchmarking for the 5 -year accreditation cycle ${ }^{12}$.

\section{Activity 1 - Core concepts}

Workshop participants were each given a stack of sticky notes and asked to write on each note, ONE concept that they considered to be key in Statics. This produced surprising variation across the group, with consensus emerging as follows:

\section{Must know:}

- Equilibrium

- Free body diagrams

- Vectors and scalars 
- Equivalent systems (forces and moments)

- Supports and reactions

- Internal vs external forces and moments

- Physical understanding

- Communication

- Problem solving and estimation techniques

- Verification of answers

- Big picture / interconnections between concepts

- Purpose of analysis

- Sign conventions

\section{Nice to know:}

- Bending moment, shear force

- Moments of area

- Centre of mass/area (centroid)

- Truss analysis

- Friction

- 2D vs 3D

- Static determinacy

- Screws / Pulleys / Wedges

- Springs

\section{Activity 2 - Discussion - Concept Tests and Concept Inventories}

There is already a body of work that addresses assessment in engineering fundamentals, namely the development of concept tests and concept inventories. The first of these was the Force Concept Inventory (FCI), developed by Thornton and Sokoloff ${ }^{13}$, originally as the Force and Motion Concept Evaluation and its history is further described by Savinainen and $\mathrm{Scott}^{14}$. The FCI arose because there was emerging concern that students were able to pass physics exams but did not necessarily understand the principles of physics and even held some non-Newtonian beliefs about how forces work.

A concept inventory has been developed for Statics, the topic of our workshop ${ }^{15}$. The authors list fundamental concepts as:

1. Free body diagrams

2. Static equivalence of combinations of forces and couples

3. Type and direction of loads at connections

4. Limit on the friction force and its trade-off with equilibrium conditions

5. Equilibrium conditions

A range of other science concept inventories have been developed, with many of them described by NCSU ${ }^{16}$. The group considered how their notion of 'concept universals' differed from these inventories.

Activity 3 - Determining quality in statics assessment items

"The extent to which an item is an optimal indicator for presence or absence of the requisite ability or knowledge. The item must be a sort of little diagnostic test for "knowledge or competence," 11 
A short overview of the AMAC findings about quality assessment items, was provided, including:

1. Defining quality

2. Tips for multiple choice item design

3. Considering the difference between selection and education-orientated testing and whether this means we should specify a (pass/fail) test for introductory statics.

The whole group was then asked to evaluate several assessment items using these steps:

1. Identify - in the subject area of the questions, what are the areas/subjects/topics we all teach? What are the problems to be solved?

2. Categorise each sample question - what is the topic or problem assessed?

3. Critique - test for relevance (specific to an engineer's required understanding of the subject)

4. Evaluate for creativity (is the question contextualised? Authentic? Realistic? Higher order? Is this an excellent way to assess this knowledge/ability? Is the wording ideal?)

5. Solve - what answers might students provide? What is acceptable? What if any partial credit will be awarded?

6. Provide feedback:

a. Identify and state the problem/s with the item

b. State why it is a problem

c. Suggest how the item could be rephrased

d. State how the revised suggestion is better than the original

7. Pairs then review and evaluate the items brought to the workshop. Pairs decide whether the item would be suitable as an assessment bank item, suitable with revision or not suitable.

\section{An Example}

The structure below consists of beam $O A B$ with arms $A C$ and $A D$ attached perpendicularly. The weight of the structure may be neglected. Point $O$ is a ball and socket joint. The ball that is attached to point $B$ slides over a frictionless slope. The angle $\alpha$ of the slope with respect to the $x$ axis is equal to tan $\alpha=3 / 4$. The structure is kept in equilibrium by means of the cables $A E$ and $C G$ which are parallel to the $x$-axis. A mass with a weight of $W=4 \mathrm{kN}$ is attached to point $D$.

Calculate the reaction(s) in B. Draw them in the figure as they act on the structure in reality.

In the first session, groups discussed assessment items and developed strategies for answering the questions, 1-7, above. There was a report back to the group.

In a second session, later in the day, it was decided that individuals could get much more

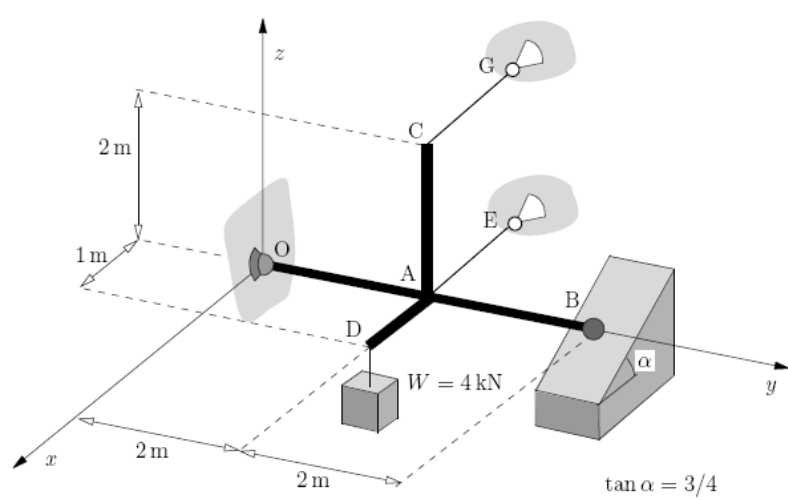
work done working alone, rather than use the group discussion method. A Google spreadsheet was setup so that everyone could access it simultaneously and insert their assessments in one column - each question had its own rows and assessors had their own column. Thus, more than one assessor could work on a particular question and assessors could progress through as many questions as they had time for. 
To simplify the process, each question was provided with the list of key concepts identified in Activity 1 and participants were asked to categorise each concept (for each question) as follows:
A. Must know in order to answer
B. Very helpful to know
C. Provides only vague context

In all, 20 participants evaluated, on average, about 12 questions each, with a maximum of 15 questions, for a total of 242 question instances. Many questions were evaluated more than once from a booklet of 98 questions. Figure 1 shows the grand totals for categories $\mathrm{A}, \mathrm{B}$ and $\mathrm{C}$ from above sorted in order of the sum of ratings $A+B / 2$ to account for a $B$ rating being of lesser value than an A rating.

Note that the three really big ideas are free body diagrams, equilibrium, and supports and reactions, which will come as no surprise to anyone. Sign conventions, vectors and scalars, physical understanding and problem solving and estimation are the next cluster of key ideas, followed by bending moments and shear force, internal and external forces and moments, and equivalent systems of forces and moments. This diagram shows a more nuanced and data driven view of the opinions expressed in Activity 1, above.

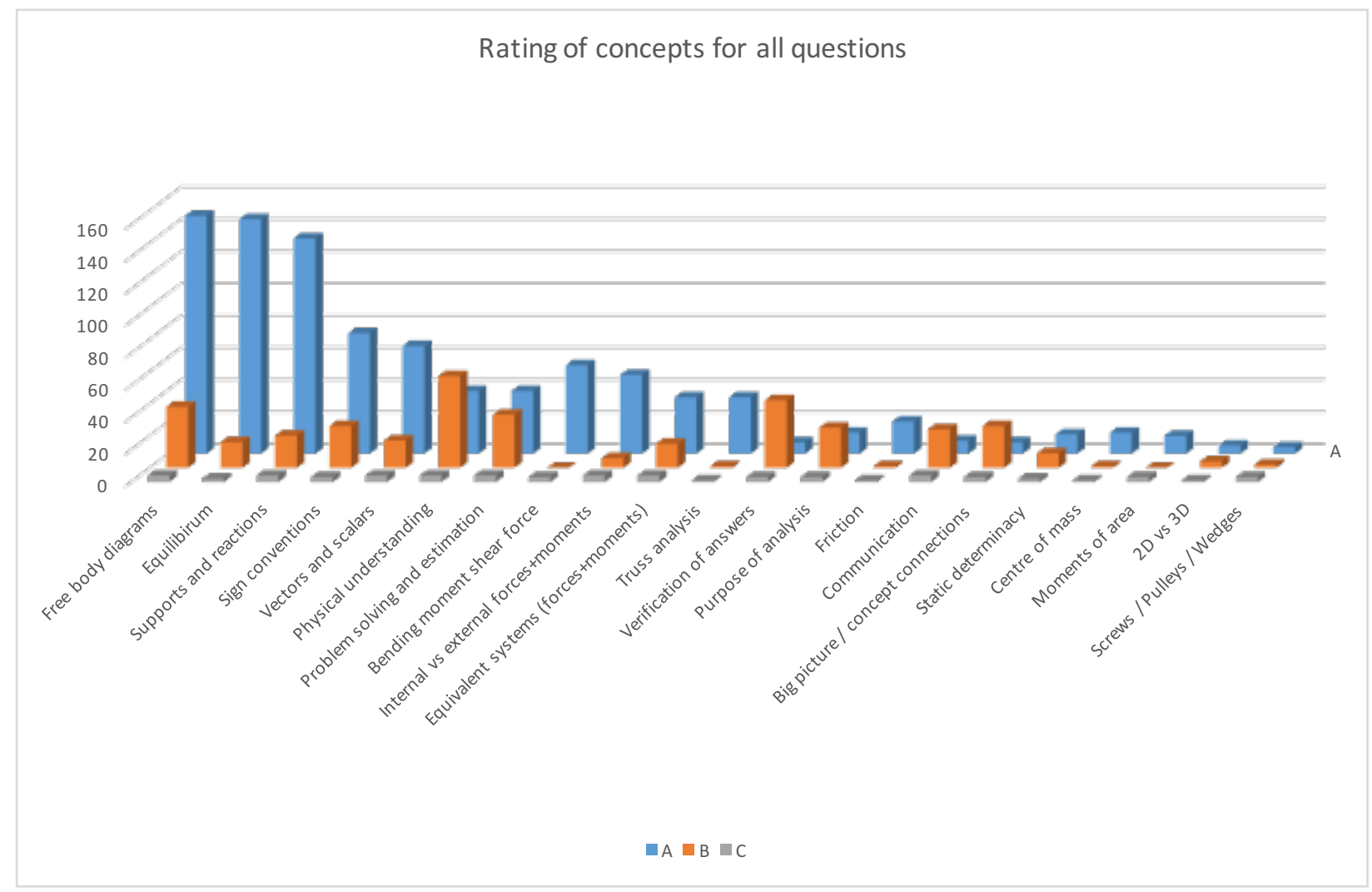

Figure 1: Rating of concepts for all questions

\section{Activity 4 - Teaching approaches}

Workshop participants also discussed their approaches to delivery of statics subjects, both in terms of pedagogy and in terms of general logistics. Identification of those elements which were of most concern was achieved by asking participants to list those aspects which they would particularly like to discuss further. This resulted in the following elements being identified:

1. Exams: How to be more creative in exam design; how to assess students' knowledge rather than just recall; logistics of marking; "gate" questions; whether an emphasis on exams is considered appropriate; 
2. Teaching approaches: how to motivate students; how to encourage self-learning;

3. Student profile: how to manage large number of students; dealing with "external" students; coping with diverse backgrounds and abilities;

4. Teaching resources: modularity to allow for customization; portability of resources and how they fit within different learning management systems; whether it is reasonable to expect students to purchase material (particularly a textbook);

5. Other support: what other forms of support are available and how does this impact on student performance - particularly tutorial support, a drop-in support centre; the use of workshops and laboratories;

6. Assessment structure: Exams vs quizzes vs labs vs tutorial problems vs projects vs design/analysis assignments vs other possibilities.

This list is interesting insofar as it clarifies those aspects that seemed to be "front-of-mind" for participants, and therefore need to be considered if we are to retain the engagement of the workshop participants in ongoing activities. There are several of these items that are especially worthy of comments.

Firstly, the mention of "gate" concepts. A significant number of the participants were concerned about the extent to which it is possible to identify (and use) questions that are critical in demonstrating understanding and which, if unable to be completed, indicate an unacceptable level of knowledge. It may be worthwhile exploring in the future the extent to which there was agreement over whether selected questions were, or were not, considered to be "gateway" questions.

A second significant issue that resulted in significant discussion related to the best approaches for dealing with significant variations in prior backgrounds and abilities. Given that statics is typically taught within an introductory unit, this variation will normally arise from previous secondary school studies. For example, commencing students may or may not have taken significant prior levels of physics or advanced mathematics studies. Finding both educational approaches and assessment materials that can develop and test core capabilities whilst also challenging advanced students was a major concern to the workshop participants.

\section{Activity 5 - Teaching core concepts}

As well as an evaluation of assessment items, there was discussion of how best to teach core concepts such as equilibrium, free-body diagrams, bending moments, etc., with an emphasis on student engagement. Engineering disasters were a popular approach. These ideas will be further developed as the collaboration grows.

\section{Activity 6 - Workshop evaluation}

At the end of the workshop, participants were asked to respond to 4 questions:

1. What was helpful?

2. What are you going to do from here?

3. Suggestions for ways forward for the group

4. What should be changed?

Of the 46 what was helpful? comments, there were three distinct themes:

(i) Strategies, ideas and resources (19),

(ii) Networking and community building (14) and

(iii) Benchmarking - being able to make comparisons with what is going on elsewhere (13). 
Academics often lead isolated lives in their own institution, unaware of good work happening elsewhere, particularly beyond the realm of their research focus. It is clear that the sharing of ideas, strategies and useful resources, was a useful outcome of the workshop, despite our intended focus on building a repository of assessment items. This might have to wait until the community is more mature and other idea sharing has occurred.

What are you going to do from here? provided 31 comments, categorised as:

(i) Concepts, Curriculum, Lectures (13);

(ii) Ideas and Resources (10);

(iii) Labs and Real world examples (8);

(iv) Assessment changes (7);

(v) Staff interactions, e.g. with this group (3).

It is interesting that only two people suggested that it would be a good idea to make better use of this group of people. The numbers sum to more than 31 because some ideas are categorized two ways. Again, the sharing of good ideas seems to dominate most people's responses.

Suggestions for ways forward for the group were categorized into 4 :

(i) Strong support for continuing exchange and meeting of the group (21 responses), including face to face meetings, online forums, videoconferences, email, etc,

(ii) Sharing of resources, ideas and strategies (11),

(iii) Sharing and review of assessment items, which had been commenced at the workshop (10), and

(iv) Curriculum change will be required (4).

Finally, the comments related to how the workshop could be changed were as follows:

(i) The structure and objectives attracted a number of comments, with aids, such as Google Docs, working well for rapid group editing (above);

(ii) The length and timing of the workshop seemed to be well received;

(iii) There was a call for more focus on teaching activities and less on assessment;

(iv) Workshop leaders and groups attracted some comments;

(v) Balance the focus on Assessment - there was as much interest in the teaching processes as there was in assessment; and

(vi) Interest in the development of a Peer think tank, with considerable value recognized in learning from each other.

\section{Participant reflection}

As a mechanics lecturer I was looking forward to attending the workshop to catch up with other participants that I already know and to meet other mechanics lecturer that I didn't yet know. Exploring the statics problems submitted to participants confirmed that most concepts were common to all participants and raised my expectations about spending time talking to fellow practitioners about the subject that we all teach.

I was disappointed then with the strongly voiced negative attitude to both the scholarship of teaching and learning and to local scholars in engineering education. I suppose I should have expected it as this attitude is pervasive in engineering faculties in Australia ${ }^{17}$. Participants' open disdain for teach and learning scholarship may go some way to explaining why existing resources are not adopted more widely - how can someone use resources that they are unaware of? This attitude may also be contributing to the focus on teaching and learning strategies rather than the assessment focus of the workshop facilitators - there is an uncritical view of exams as 
assessment tasks and/or the vocal participants are unaware of the critical role of assessment in driving what students actually learn.

The attitude that they have to create their own resources consolidates their view of themselves as the 'expert' in the classroom i.e. 'the sage on the stage' rather than the 'guide on the side'. This view of themselves is demonstrated in the move to individual rating of the questions in the workshop rather than taking the time to collaboratively unpack each question and generate shared understandings of the concepts tested.

While I expressed interest in the ongoing activities of this group I feel like it's one more thing to find time for in an already overstretched workload. Also I was able to attend this workshop because it was held in the city where I live. If it had been held somewhere else, I would not have been able to attend as I have no access to discretionary funds for travel and accommodation to these types of professional development events. For those without such discretionary funding the ongoing life of this group will depend on line managers' (Heads of Schools') goodwill.

Perhaps a way forward for the group is to source and share examples of active and collaborative learning activities in statics which align with what most participants said they were looking for and then to use these activities to broach the subject of how best to assess conceptual understanding. Changing the culture with respect to scholarship of teaching and learning is beyond the scope of any one project.

\section{Conclusions}

The workshop proved the value of bringing together academics who teach engineering fundamentals. A little over half the universities in Australia who teach engineering were represented. Interestingly, there was more interest in gathering ideas and strategies for teaching statics than there was in developing some standard assessment items, despite this being the focus of the workshop.

It is likely, however, that a focus on enhanced teaching in statics will lead to deeper consideration of assessment. This collegial aspect of the workshop also highlighted the isolation that lecturers typically feel in relation to delivery of their subjects and also provided an opportunity for self-reflection and improvement.

The workshop activities demonstrated the willingness of participants to problematize those aspects of their subjects that they had previously taken for granted, including what constitutes essential concepts and the sequence in which they should be taught.

There is a small group of participants who are interested in keeping the group collaborating. Some effort will be devoted to this in 2016, which will also see a second workshop, likely for an electrical engineering topic, e.g. circuit analysis, and this will be the subject of a future paper.

Other national and state-based groups of universities are encouraged to follow our lead and share their understanding of teaching Statics and other engineering fundamentals. An international collaboration on the development of assessment items in these areas would be valuable to us all.

\section{Acknowledgements}

Thanks to the workshop participants for their unflagging enthusiasm over the two days and also to the reviewers for their insightful comments, which have resulted in a better paper. 


\section{References}

1. Boles, W., et al., Creating efficiencies in teaching: where are the right resources when you need them?, in Australasian Association for Engineering Education Conference, C. Lemckert, G. Jenkins, and S. LangLemckert, Editors. 2013, Griffith University: Gold Coast.

2. Downes, S., Models for sustainable open educational resources. Interdisciplinary Journal of Knowledge and Learning Objects, 2007(3): p. 29-44.

3. Yuan, L., S. MacNeill, and W. Kraan. Open educational resources - Opportunities and challenges for Higher Education. Open Educational Resources Briefing Paper 2008; Available from:

https://oerknowledgecloud.org/sites/oerknowledgecloud.org/files/OER Briefing Paper.pdf.

4. McCarthy, T., et al. A pro-active approach to addressing student learning diversity in engineering mechanics. 201029 Aug, 2015]; Available from: http://www.olt.gov.au/system/files/resources/CG8695 UoW McCarthy Final Report 2011 0.pdf.

5. Foley, B. and C. Willis. Promoting student engagement and continual improvement: Integrating professional quality management practice into engineering curricula. 201531 Jan 2016]; Available from: http://www.olt.gov.au/project-promoting-student-engagement-and-continual-improvement-integratingprofessional-quality-mana.

6. Lowe, D., et al. Remotely Accessible Laboratories - Enhancing Learning Outcomes. 20084 Feb 2016]; Available from: http://www.olt.gov.au/resource-remotely-accessible-labs-uts-2008.

7. ARNEIA. Projects. 2015 [cited 201529 Aug]; Available from: http://www.arneia.edu.au/projects.

8. AAEE-Scholar. Engineering Mechanics. 2015 [cited 201529 Aug]; Available from: http://aaeescholar.pbworks.com/w/page/1177038/Eng mechanics.

9. Pannam. 50 Top Resources to Learn Electrical Engineering Online for Free. 201529 Aug 2015]; Available from: http://www.pannam.com/blog/free-resources-to-learn-electrical-engineering.

10. SkilledUp. Learn Engineering Online for Free with Our Huge Collection of Open Courses and Textbooks. 201529 Aug 2015]; Available from: http://www.skilledup.com/articles/learn-engineering-online-free.

11. Australian Medical Assessment Collaboration. Determining the Quality of Assessment items in Collaborations: Aspects to discuss to reach agreement. 201327 Jan 2016]; Available from: http://www.olt.gov.au/resource-Australian-medical-assessment-collaboration.

12. Engineers Australia, Accreditation Criteria and Guidelines. 2006, Engineers Australia: Canberra.

13. Thornton, R.K. and D.R. Sokoloff, Assessing student learning of Newton's laws: The Force and Motion Conceptual Evaluation and Evaluation of Active Learning Laboratory and Lecture Curricula. Amer J Physics, 1998. 66: p. 338-352.

14. Savinainen, A. and P. Scott, The Force Concept Inventory: a tool for monitoring student learning. Physics Education, 2002. 37(45).

15. Steif, P.S. and J.A. Dantzler. A Statics Concept Inventory: Development and Psychometric Analysis. n.d. [cited 201529 Aug]; Available from: http://engineering-education.com/Steif-Dantzler.pdf.

16. NCSU. Assessment Instrument Information Page. n.d. [cited 201529 Aug]; Available from: http://www.ncsu.edu/per/TestInfo.html.

17. Cretchley, P.C., et al., Research and/or learning and teaching: a study of Australian professors' priorities, beliefs and behaviours. Higher Education Research \& Development, 2014. 33(4): p. 649-669. 